\title{
Driver Drowsiness Detection System
}

\author{
Deepa Malimath and Komal Jain
}

\begin{abstract}
In Indonesia, based on data from police, from the 2007-2010 at least 218253 number of accidents occur. Approximately $65 \%$ of accidents occur due to human negligence. At the time of Eid 23 August to 7 September 2011, the number of accidents that occur most often caused by drowsy drivers (1,018 cases), followed by airworthiness vehicles (449 cases), roadworthiness (387 cases), and speed (155 cases). Drowsiness detection system created to reduce the risk of accident while driving. The system will records image of driver then face and eyes will be detected. Results of eyes detection, each frame value will be analyzed if eyes are closed for 4 seconds. If eyes close for 4 seconds then system will decide that driver is sleepy and alarm will sound. From the experiment, average result for detection is $954 \mathrm{~ms}$, best position of camera is above the driver on the dashboard and for bright condition.
\end{abstract}

Keywords--- Eyes Detection, Drowsiness Detection System, Computer Vision, Image Processing.

\section{INTRODUCTION}

$\mathrm{F}$ OR less than 100 years, private car has changed from an eccentric mass commodity product with the highest technology and very low cost. Vehicle performance continuously improved during the last century. Not just a matter of speed, but also the handling, braking, comfort, safety, reliability, and most importantly, safety. The car also has become a huge industry that forces the economy of a country. Not only for the manufacture of products, but also for maintenance, exploitation, processing and Distribution of petroleum products, building a highway construction, etc.

Based on data from Indonesia National Police, from the 2007-2010 at least 218.253 number of accidents occur. Approximately $65 \%$ of accidents occur due to human negligence. At the time of Eid 23 August to 7 September 2011, the number of accidents that occur most often caused by drowsy drivers (1,018 cases), followed by airworthiness vehicles (449 cases), roadworthiness (387 cases), and speed (155 cases).

\section{DETECTION METHOD}

Drowsiness is a process where level of consciousness decrease due to lack of sleep or fatigue and can cause a person falls asleep. When driver is drowsy, the driver could lose

Deepa Malimath, Student, Dept of CSE, SKSVMACET, Laxmeshwar India. E-mail:deepumalimath@gmail.com

Komal Jain, Student, Dept of CSE, SKSVMACET, Laxmeshwar - India. E-mail:komalj704@gmail.com

DOI:10.9756/BIJSESC.8243 control of the car so it was suddenly possible to deviate from the road and crashed into a barrier or a car.

Types of biological indicators of sleepiness identify brain waves, heart rate, and pulse signals. This technique produces the best detection accuracy but requires physical contact with the driver. The second types of behavioral measures are vehicle speed, lateral position, and rotation angle. This technique can be implemented, but there are restrictions such as vehicle type, driver experience, as well as in driving condition. This technique also requires specialized and expensive equipment.

The third type is the analysis of the face. Although this technique is more accurate than the biological indicator, this technique is non-intrusive and easy to implement, and no dependency between the driver's experience with the type of vehicle. The limitations to this technique are lighting conditions and driver distances from camera.

Drowsiness detection techniques, in accordance with the parameters used for detection is divided into two sections i.e. intrusive method and a non-intrusive method. The main difference of these two methods is that the intrusive method, an instrument connected to the driver and then the value of the instrument are recorded and checked. But intrusive approach has high accuracy, which is proportional to driver discomfort, so this method is rarely used. Drowsiness detection techniques are generally classified into three groups: methods based on the condition of the driver, the method based on the performance of the driver, and the combined of the previous method ${ }^{[1]}$.The method based on the condition of the driver is divided into two categories, namely: a technique using physiological signals and image-based techniques.

The method based on the condition of the driver is divided into two categories, namely: a technique using physiological signals and image-based techniques. The first method uses physiological and non-visual symptoms created by the body when sleepy. For this purpose, the first electrode will be connected to the body of the driver and will record the electrical activity in certain parts of the body i.e. brain, muscle, heart, etc. Signal that has been recorded earlier will be analysed to determine the driver's level of drowsiness. The use of 30 electrodes in a group when the driver indicates that sleepiness increases the signal level theta and alpha activity also increased ${ }^{[2]}$. This method produces good accuracy but is not recommended for use because it does not interfere and make the driver comfortable.

Fatigue and sleepiness create distinct markings on the face. Signs were used to detect image-based drowsiness. The first step is to detect the face of the driver first, and then the parameters for detecting drowsiness extracted and used to 
detect sleepiness ${ }^{[3]}$. Vural et al ${ }^{[4]}$ in a study examining the relationship between steering angle with the driver's head movement. Results of the study showed that the correlation between the movements of the steering angle on the head with a sleepy driver is higher than the driver alert.

Several research related to drowsiness detection system have been done by Chau andBetke ${ }^{[5]}$ regarding eye tracking and flicker detection. Eye tracking is done in real time by determine location of the eyes based on the image of facial using creating eye template and comparing its value. This research was focus on blinking detecting of the eyes. Research which conducted by Chau have not been capable to distinguish where eye who closed and where eye which just blinking. At the time of eye closed the area eye always can be detected, but not yet could to distinguish where eyes who open or closes. Zoroofi $^{[6]}$ by adding algorithm to determine location of pupil and iris eye. Eye area detected using Eye Map algorithm, after eyes successfully found, then there will be detected the pupil namely center of from eye. After pupil successfully detected then next stage is to detect retina which constitute the outer circle of the pupil.Other research conducted by Tabrizi and the results of this research still experiencing constraints on the determination of location of pupil that still not yet precision, besides that the calibration also must always be done because the size of window always change. This research uses parameter from PERCLOS as a reference to determine whether someone is defined sleepy or not.

\section{On PERCLOS duration of person blinking normally}

is 0.3 seconds. If someone is considered sleepy then the usually distance between eyelids the eyes would become increasingly more width. This research uses a good method because capable detecting for various sizes of the eye types but still not yet could to perform tracking from pupil which successfully detected.

\section{A. Global Architecture System}

Development is done on the area of the driver with the environment around him. In the architecture of the system below the driver is connected with a variety of features that exist around him. The system architecture is divided into four parts namely, the main driver of computer (DMC), obstacle avoidance computer (OAC), driver auxiliary computer (DAC), and the navigation computer (NC). DMC consists of a head-up display (HUD) and the drowsiness detection system (DDS). HUD displays a variety of information received from the OAC and the existing ECU sensors on the engine (including: speed, rpm, temperature, and fuel gauge). In the area there are also driver DDS will record the image of the driver while driving. When it is detected that the driver is drowsy then DDS will sound an alarm to wake the driver. Overall system architecture is shown in Figure I below.

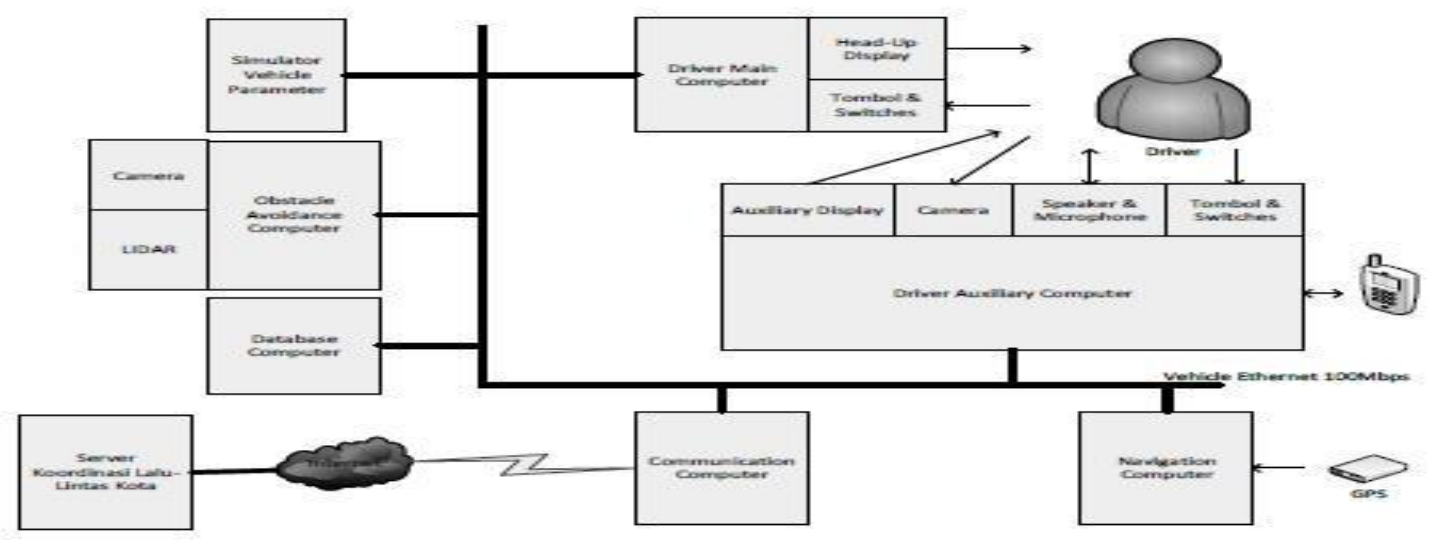

Figure 1: Global Architecture System

While OAC consists of a sensor in front of the vehicle that serves to capture all the objects that are in front of the vehicle (whether still or moving) and then analyzed to generate recommendations of information for driver and they will be sent via LAN and displayed in the HUD.

The information sent in audio and visual information form so that drivers get information visually through HUD and the audio. DAC consists of features that support communication in a vehicle. Application is designed for DAC that allows drivers to perform activities to communicate with the phone without doing a lot of interaction.
Communications at DAC is designed using Bluetooth so the driver can simply activate the Bluetooth from the phone, and speech recognition to minimize interactions. Various purposes such as IM, phone calls, receive calls, as well as play audio files can be performed using speech recognition. While driving. Navigation here is designed offline and online. Driver simply activates the existing GPS sensor in your phone and then selects the goals then the application will display the shortest route along with mileage and time predictions are achieved. In addition, the system will also provide different routes for each vehicle depends on the density of the road when it's available.

Data communication is done by using the LAN to exchange data. At this architecture is designed using $\mathrm{Wi}-\mathrm{Fi}$ 
communication that minimizes the number of wires in the system. The system architecture also consists of a database to store various kinds of data from the driver's log, map navigation, voice, and various other data.

\section{B. Drowsiness Detection System Design}

DMC architecture is described in figure II below. DMC consists of HUD and drowsiness detection system.

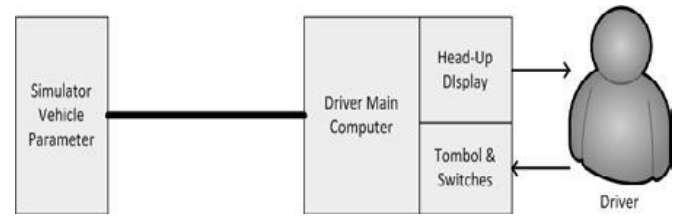

Figure 2: DMC Architecture

In this architecture, data is provided as well as the parameters vehicle simulator for testing the data complement system. Parameters used including data speed, engine rotation speed, temperature, and fuel gauge. For drowsiness detection system, the data parameter that is used as a measure of the speed of the vehicle how long it takes for the system to assume the driver was sleepy in accordance with vehicle speed.

Drowsiness detection system is designed to use a camera sensor on the front of the driver that is connected to an application. The sensor will detect the condition of the driver continuously, especially in the eye, when the eye is considered sleepy then the application will immediately sound an alarm to wake the driver. The system will also be linked into the application that will take a wide variety of data from sensors attached to the engine control unit of a vehicle. The process of determining how long a driver was considered too sleepy determined from vehicle speed. Drowsiness detection system design is shown in Figure 3 below

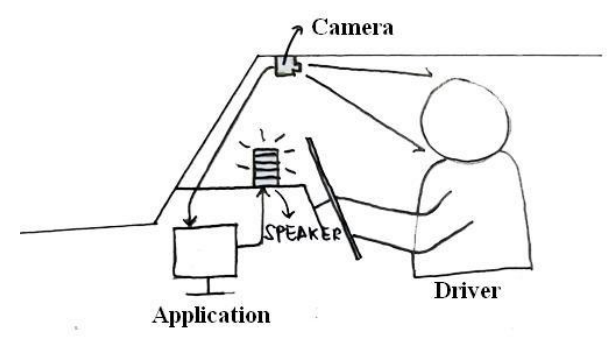

Figure 3: Drowsiness driver system design

\section{Driver Drowsiness System Specification}

Driver drowsiness detection system is divided into three main blocks, i.e. camera, speaker, and applications for detecting driver drowsiness. Camera block record the driver's facial image and submit it to the drowsiness detection applications as processing input. Processing will take place at any time in real-time, when it was discovered that the driver was in a state of drowsiness then the application will send a sound through the speakers to wake the driver. Drowsiness detection system blocks are made is shown by the following Table 1.

Table 1: Drowsiness Detection System Specification

\begin{tabular}{|l|l|l|l|}
\hline Block & Interface & Block relation & Function \\
\hline Camera & $\begin{array}{l}\text { web } \\
\text { camera } \\
1 \mathrm{pc}, \text { in } \\
\text { front of } \\
\text { driver }\end{array}$ & $\begin{array}{l}\text { connect to } \\
\text { application } \\
\text { through USB }\end{array}$ & $\begin{array}{l}\text { input to get } \\
\text { images of } \\
\text { driver }\end{array}$ \\
\hline Speaker & $\begin{array}{l}\text { active } \\
\text { speaker, } \\
1 \mathrm{pc}\end{array}$ & $\begin{array}{l}\text { connect to } \\
\text { application } \\
\text { through audio } \\
\text { port }\end{array}$ & $\begin{array}{l}\text { output to } \\
\text { sound } \\
\text { warning to the } \\
\text { driver }\end{array}$ \\
\hline Application & $1 \mathrm{PC}$ & $\begin{array}{l}\text { Connect to camera } \\
\text { and speaker to } \\
\text { receive input and } \\
\text { send from } \\
\text { analysed image. }\end{array}$ & $\begin{array}{l}\text { Detect } \\
\text { drowsiness } \\
\text { from image } \\
\text { from camera } \\
\text { and send } \\
\text { warning to } \\
\text { driver }\end{array}$ \\
\hline
\end{tabular}

Table 2: User Specification

\begin{tabular}{|l|l|}
\hline Specification & Description \\
\hline User & Driver \\
\hline Car & family / city car \\
\hline Gender & Male / Female \\
\hline Age & $20-65$ \\
\hline Wearing glasses & No \\
\hline
\end{tabular}

Table 3: Functional Specification

\begin{tabular}{|c|c|c|}
\hline Function & Interaction & Description \\
\hline $\begin{array}{l}\text { Detect face of } \\
\text { driver }\end{array}$ & $\begin{array}{l}\text { webcam - face } \\
\text { of driver }\end{array}$ & $\begin{array}{l}\text { Webcam records the face } \\
\text { of driver and then } \\
\text { searched the area of the } \\
\text { face, if the face is found } \\
\text { then eye detection process } \\
\text { is done, but when the face } \\
\text { is not found then the eye } \\
\text { detection process will not } \\
\text { be done again. }\end{array}$ \\
\hline $\begin{array}{l}\text { Detect the eyes } \\
\text { of driver }\end{array}$ & $\begin{array}{l}\text { webcam-eyes } \\
\text { of driver }\end{array}$ & $\begin{array}{l}\text { After successfully } \\
\text { detected the driver's face, } \\
\text { the next process is to find } \\
\text { the eyes of driver } \\
\text { obtained by face. }\end{array}$ \\
\hline $\begin{array}{l}\text { Detect the } \\
\text { drowsiness of } \\
\text { driver }\end{array}$ & $\begin{array}{l}\text { Webcam-eyes } \\
\text { of driver. }\end{array}$ & $\begin{array}{l}\text { Once the eyes are found, } \\
\text { later determined the } \\
\text { driver's eyes closed for a } \\
\text { while or not. Closed } \\
\text { boundaries here is } 3 \\
\text { seconds, eyes closed if for } \\
3 \text { seconds then the driver } \\
\text { is considered sleepy. If } \\
\text { only elosed } 1 \text { second then } \\
\text { considered blink. }\end{array}$ \\
\hline Warn the driver & $\begin{array}{l}\text { computer - } \\
\text { speaker }\end{array}$ & $\begin{array}{l}\text { If the driver is considered } \\
\text { sleepy then computer will } \\
\text { play audio file through } \\
\text { speaker. }\end{array}$ \\
\hline
\end{tabular}

\section{Drowsiness Driver System Flowchart}

In this system, the camera will always record the image of the driver at all times which will then detect a face, then detect eyes. If detected eyes are closed for a moment, then the system will send a warning sound to wake the driver. If detected that eye blink then just do not do any action and still images recorded by the camera. Flowchart for drowsiness detection system is shown in Figure 4 below. 


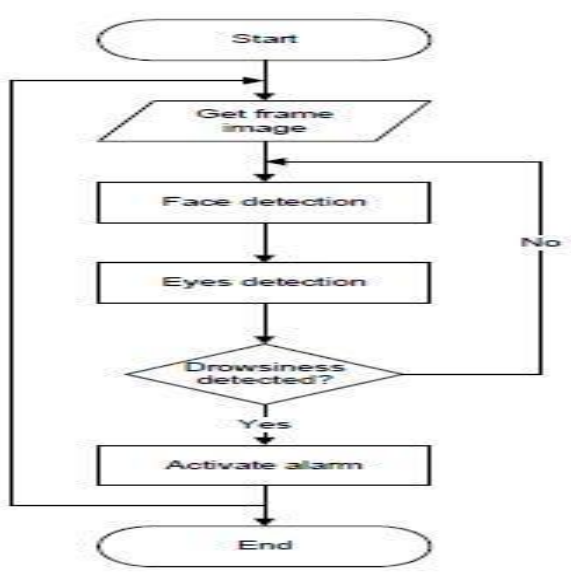

Figure 4: Drowsiness Detection System Flow Chart

\section{IMPLEMENTATION AND TESTING}

\section{A. Global Architecture System}

Drowsiness detection application is made using Microsoft Visual Studio C++ 2010 which is running on Microsoft Windows 7 operating system. Application is made using procedural programming using function which is provide by compiler. From implementation we get executable file helloEyes.exe, to run detection process. This application uses some additional libraries, which are as follows.

1) Open $\mathrm{CV}$, libraries used to perform image processing and driver drowsiness detection process conditions.

2) Winmm.lib, libraries to run an audio file of the $\mathrm{C}++$ program.

3) MM System. h, library headers related to operations related to multimedia files.

\section{B. Detection Testing}

Detection testing aims to determine under what conditions the driver's face can be detected by the system. Detection test was conducted in three time periods i.e. morning, noon, and night and in the dark and two light conditions. Stages of the detection is done by taking the input face image then interpolated to a smaller size to save time searching. After interpolated, then image is converted into grey scale form. Interpolation results and changes into grey scale form shown in Figure 5 below.

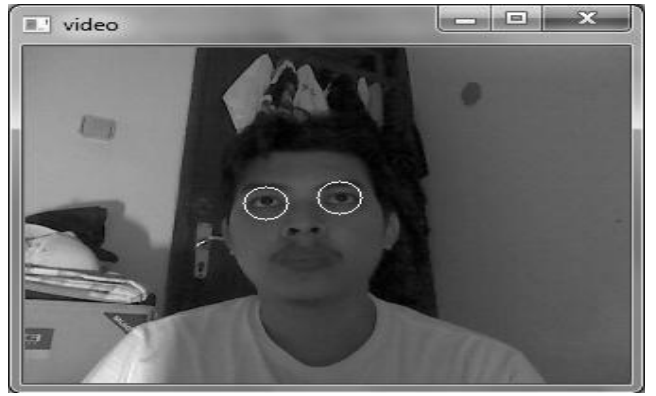

Figure 5: Interpolation Result
Stages after threshold interpolation is used to convert a grey scale image into binary because the computer is only able to read the binary value of the data received by the computer. After pass threshold stage, the image will be black and white according to the threshold value that has been set previously.

Threshold value is set to 255 , which means that for a 255 pixel RGB value will be set to white, in

addition to 255 will be set to black.

Stages of face and eye detection is done as follows

\section{a. Getting Haar Training Values}

Training value is obtained from the classifier that contains the training data has been done before. The training process obtains a sample of the images from the cameras and compared with values in Open CV. Frame rate will be used to detect whether the object image is a face or not.

\section{b. Determining ROI (Region of Interest) on the images}

Region of Interest is a rectangular area that is used to determine the position of an object or area required for further processing in the system. An example is taken the position of the face area of the image were detected as shown in Figure 6 below.

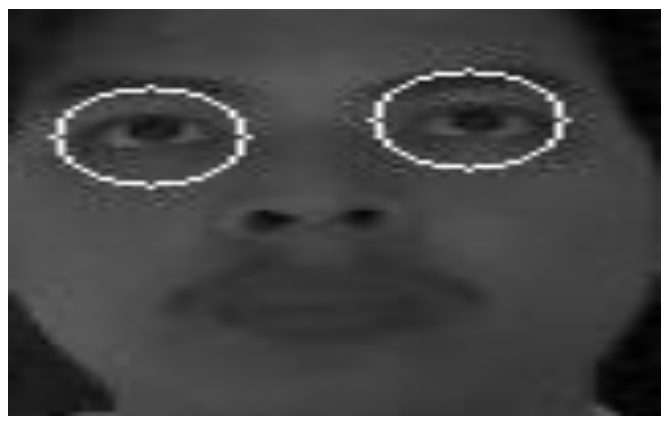

Figure 6: Getting ROI from the Image

By getting ROI, detection process becomes faster because the scope of searching becomes smaller so there are no need to compare all of the values to determine which area is eyes.

\section{c. Projection Integral}

After face is detected, next process is calculating integral projection to determine area of the eyes. Here, area of the eyes is assumed 1/3 from top of face. Object searching starts from sub window with $24 \times 24$ size of scale on whole face. Searching will be looped using rescaled sub window as shown in figure 7 below.

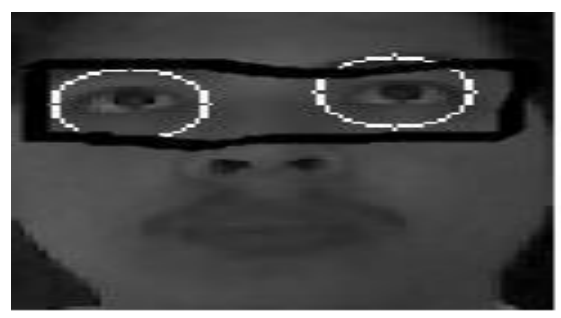

Figure 7 


\section{d. Eyes detection}

After area of the eyes is determined then we search the eyes. Eyes searching in sub windows based on XML classifier (haarcascade_eye.xml). To create XML classifier, method gentle ad boost is used, by looking features which have high degree of differentiation. This is done by evaluating every feature to training data using value of each feature. Feature which has the greatest range value between eyes and not eyes is considered as the best feature. Detection process is shown in Figure 8 below.

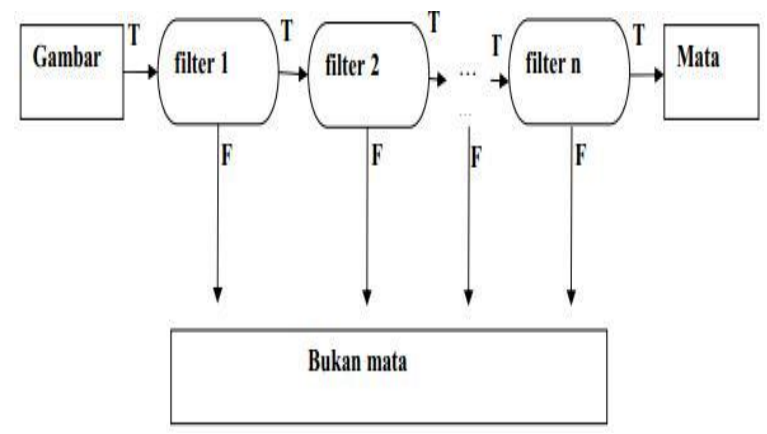

Figure 8: Detection process using XML Classifier

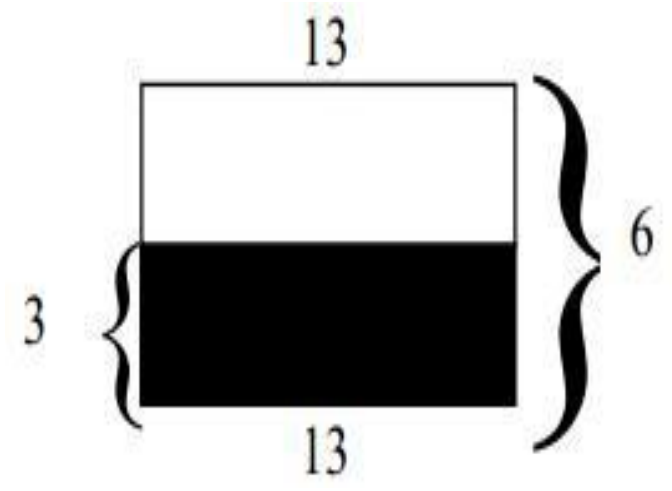

Figure 9: Haar Feature Description

On first classification (filter 1), every sub image will classified using one feature. This classification will leave $50 \%$ of sub images to be classified on stage two (filter 2) Along with the increased levels of classification, so we need specific requirement to use more feature. Amount of sub images which pass classification process will reduce to approach images in sample (data .xml) or until the classification process just left $2 \%$ of sub images. The value of feature can be calculated using image integral. Example of calculation using image integral is shown in Figure 9 below.

Frame value will be compared to threshold value ($0.0202897991985083)$, if the value is smaller than left value $(0.5025501251220703)$ will return; and if bigger then right value(-0.4522908926010132) will return. After that, feature is processed until the last feature. If the return value for all feature is smaller than stage threshold (-1.3585350513458252) then it is the sub window, if not then another stage will be processed until there is a decision that eyes is found or not.
Table IV: Detection Testing

\begin{tabular}{|c|c|c|}
\hline Scenario & Expected Result & Result \\
\hline $\begin{array}{l}\text { Detection in the } \\
\text { morning with bright } \\
\text { conditions }\end{array}$ & \multirow{6}{*}{$\begin{array}{ll}\text { application can } & \text { detect } \\
\text { drowsiness } & \text { driver } \\
\text { system } & \end{array}$} & $\begin{array}{l}\text { drowsiness } \\
\text { detected }\end{array}$ \\
\hline $\begin{array}{l}\text { Detection in the } \\
\text { morning with dark } \\
\text { conditions }\end{array}$ & & $\begin{array}{l}\text { drowsiness } \\
\text { detected }\end{array}$ \\
\hline $\begin{array}{l}\text { Detection during } \\
\text { the day with light } \\
\text { conditions }\end{array}$ & & $\begin{array}{l}\text { drowsiness } \\
\text { detected }\end{array}$ \\
\hline $\begin{array}{l}\text { Detection during } \\
\text { the day with the } \\
\text { dark }\end{array}$ & & $\begin{array}{l}\text { drowsiness } \\
\text { detected }\end{array}$ \\
\hline $\begin{array}{l}\text { Detection at night } \\
\text { with the light } \\
\text { conditions }\end{array}$ & & $\begin{array}{l}\text { drowsiness } \\
\text { not detected }\end{array}$ \\
\hline $\begin{array}{l}\text { Detection at night } \\
\text { with dark } \\
\text { conditions }\end{array}$ & & $\begin{array}{l}\text { drowsiness } \\
\text { not detected }\end{array}$ \\
\hline
\end{tabular}

\section{Time Detection Testing}

Long testing time detection performed by taking samples detected on multiple computers with different specifications and then calculated the average of these samples to obtain a long time of testing. The number of samples used 30 times reading/ detection.

Table V: Time Detection Testing

\begin{tabular}{|l|l|l|}
\hline Sample & $\begin{array}{l}\text { Amount of } \\
\text { detection }\end{array}$ & Time \\
\hline Bright condition & 30 sample & $894 \mathrm{~ms}$ \\
\hline $\begin{array}{l}\text { Cloudily } \\
\text { condition }\end{array}$ & 30 sample & $927 \mathrm{~ms}$ \\
\hline Video sample & 30 sample & $1043 \mathrm{~ms}$ \\
\hline
\end{tabular}

From the results of the implementation of drowsiness detection system performed the following analysis.

1) Drowsiness detection application is still dependent on the distance between the camera and the face of the driver, the driver's position relative to the camera, and lighting conditions. The best camera position obtained at the top of the driver, because of the light coming from outside are not collected so that the lighting conditions are relatively stable and easy to detect.

2) Drowsiness detection application has not been able to detect the eyes are too narrow as in the East Asian race.

3) Drowsiness detection application is still using the default classifier whose size is large enough so that there is always a delay to prepare a classifier that will 
be used for detection.

4) The system is still not able to detect image when dark conditions. The solution could be to use a web camera that supports infrared rays to obtain images in the dark.

\section{CONCLUSION}

From the results of the testing and analysis of the implementation of some of the conclusions obtained as follows.

1) Detection process can be performed either during the day or night. Detection failed to take place at night because the object is too dark so it was hard to recognize.

2) Long detection times around $954 \mathrm{~ms}$ with 30x sample face and eye detection.

3) Making classifier containing facial image data eyed people (race East Asia) that can detect people with slanted eyes.

\section{REFERENCES}

[1] P.R. Knipling and S.S. Wang, "Revised Estimatesof the use drowsy driver crash problem size based on general estimates system case reviews", The 39th Annual Proceedings of Association for the Advancement of Automotive Medicinea, 1995.

[2] J.S. Wang, R.R. Knipling and M.J. Goodman, "The role of driver inattention in crashe", new statistics from the 1995 crashworthiness data system, The 40th Annual Proceedings of Association for the Advancement of Automotive Medicine, 1995.

[3] M.A. Assari and M. Rahmati, "Driver Drowsiness Detection Using Face Expression Recognition", IEEE International Conference on Signal and Image Processing Applications, 2011.

[4] E. Vural, M. Jdatcetin, A. Ercil, G. Littlewort, L. Bartlett and J. Movellan, "Machine Learning System for Detecting Driver Drowsiness", In Vehicle Corpus and Signal Processing for Driver Behavior, Springer, Pp. 97-110, 2009.

[5] C. Michael and B. Margrit, "Real Time EyeTracking and Blink Detection with USB Cameras", Boston University Computer ScienceTechnical Report No, Pp. 12, 2005, 2005.

[6] P.R. Tabrizi and R.A. Zoroofi, "Open/ClosedEye Analysis for Drowsiness Detection", ImageProcessing Theory, Tools \& Applications, 2008 .

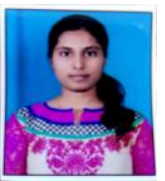

Deepa Malimath, Student, Dept of CSESKSVMACET, LaxmeshwarIndia.

(E-mail:deepumalimath@gmail.com)

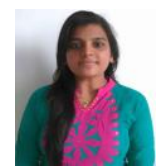

Komal Jain, Student, Dept of CSE

SKSVMACET, Laxmeshwar - India.

(E-mail:komalj704@gmail.com) 